\title{
La multa coercitiva y la suma a tanto alzado en el recurso por inejecución de sentencia ante el Tribunal de Justicia de la Unión Europea
}

\author{
Teresa Acosta Penco \\ Área de Derecho Administrativo \\ Universidad de Córdoba
}

\begin{abstract}
SUMARIO: I.INTRODUGGIÓN: DEL REGURSO POR INGUMPLIMIENTO AL REGURSO POR INEJEGUGIÓN DE SENTENCIA. II. EL PROCEDIMIENTO POR INCUMPLIMIENTO DE LA OBLIGACIÓN DE ADOPTAR LAS MEDIDAS NEGESARIAS PARA LA EJEGUCIÓN DE LA SENTENCIA: 1. Legitimación de las partes. 2. Objeto del recurso por inejecución de sentencia. 3. Fase precontenciosa. 4. Fase jurisdiccional. III.LA MULTA COERCITIVA Y LA SUMA A TANTO ALZADO: 1. La colaboración de la Comisión en la interpretación y aplicación de la multa coercitiva y la suma a tanto alzado. 2. La no vinculación del TJUE a la propuesta de la Comisión. 3. La multa coercitiva y la suma a tanto alzado como medidas de ejecución, la cuestionada doble imposición. 4 . El confuso debate sobre la naturaleza sancionadora o no de estas medidas. 5. Cálculo de la multa coercitiva. 6. Cálculo de la suma a tanto alzado. 7. Ejecución de la multa coercitiva y de la suma a tanto alzado. IV. BREVES CONCLUSIONES. V. BIBLIOGRAFÍA. VI. ÍNDIGE JURISPRUDENGIAL.
\end{abstract}

RESUMEN: El presente artículo se centra en la evolución, naturaleza y ejecución de la multa coercitiva y la suma a tanto alzado como medidas pecuniarias que han previsto los Tratados de la Unión Europea para garantizar la aplicación efectiva del Derecho de la Unión por parte de los Estados miembros. Para comprender el contexto en el que se desarrollan estas medidas se ha comenzado desarrollando el procedimiento por inejecución de sentencia regulado en el art. 260.2 del Tratado de Funcionamiento de la Unión Europea. En virtud del mismo y para aquellos casos en que los Estados no ejecuten una sentencia declarativa de incumplimiento, la Comisión Europea, tras la tramitación de una fase precontenciosa, puede solicitar al Tribunal de Justicia de la Unión Europea que imponga una serie de medidas pecuniarias para inducir al Estado miembro incumplidor a que cumpla con lo dispuesto en la sentencia anterior. 
PALABRAS CLAVE: Procedimiento de incumplimiento, procedimiento por inejecución de sentencia, Tribunal de Justicia de la Unión Europea, Comisión Europea, multa coercitiva, suma a tanto alzado.

ABSTRACT: This paper focuses on the evolution, nature and enforcement of penalty payment and lump sum as financial measures foreseen in the Treaties of the European Union to ensure the effective implementation of EU Law by the Member States. To understand the context in which these measures are developed, this paper firstly delves into the infringement procedure established in the article 260.2 of the Treaty on the Functioning of the European Union. For those cases where Member States do not run the declaratory judgment of non-compliance, the European Commission, after a pre-litigation phase, requests the European Court of Justice to impose a series of financial measures to induce the defaulting Member State to comply with the provisions of the previous sentence.

KEY WORDS: Infringement proceedings, European Court of Justice, European Commission, penalty payment, lump sum.

\section{INTRODUCGIÓN: DEL REGURSO POR INGUMPLIMIEN- TO AL REGURSO POR INEJEGUGIÓN DE SENTENGIA}

El principio de cooperación leal entre los Estados miembros y la Unión es uno de los más importantes del ordenamiento de la Unión, ello explica que los Tratados declaren la obligación que recae sobre dichos Estados de adoptar todas las medidas necesarias "para asegurar el cumplimiento de las obligaciones derivadas de los Tratados o resultantes de los actos de las Instituciones de la Unión" (art. 4.3.2 TUE). Por ello es lógico que el TFUE prevea un mecanismo para controlar el cumplimiento de esas obligaciones. Este mecanismo es el procedimiento de incumplimiento, regulado en los artículos 258 a 260 TFUE $^{1}$.

\footnotetext{
${ }^{1}$ En relación con este procedimiento, ver con carácter general: M. BACigalupo SAGGESE, "El sistema jurisdiccional de la Unión Europea" en Principios de Derecho de la Unión Europea, coord. E. LiNDe Paniagua, Colex, Madrid, 2011, p. 544 y ss.; R. Alonso García, Sistema Jurídico de la Unión Europea, Civitas, Madrid, 2007; M. Gómez De Liaño Fonseca, "La garantía jurisdiccional del Derecho Comunitario" en Instituciones de Derecho Comunitario, Colex, Madrid, 2009; J. A. Girón LarRUCEA, La Unión Europea. La Comunidad Europea y el Derecho Comunitario, Universidad de Sevilla, Sevilla, 2002, pp. 565 y ss.; L. Prete and B. SMulders, "The coming of age of infringement proceedings", Common Market Law Review, nº 47, 2010, pp. 9-61; F. Díez Moreno en Manual de Derecho de la Unión Europea, Civitas, Navarra, 2009, pp. 323 y ss.; A. SÁnchez LegIDO, "El sistema judicial comunitario", en Instituciones de Derecho Comunitario, coord. R. Huesa VinaIXA, Tirant lo Blanch, Valencia, 2000, pp. 243-316; y D. Ruiz Jarabo-Colomer, La justicia de la Unión Europea, Civitas, Navarra, 2011, pp. 130 y ss.
} 
Como es sabido, una sentencia dictada por el TJUE en el marco de un recurso de incumplimiento interpuesto al amparo de los artículos 258 ó 259 TFUE tiene una naturaleza exclusivamente declarativa, de manera que su principal efecto es el de obligar al Estado miembro cuyo incumplimiento ha sido declarado a adoptar todas las medidas necesarias para la ejecución de la misma. No obstante, la declaración judicial de incumplimiento lleva también aparejada la obligación del Estado demandado de, según el art. 260.1, TFUE "adoptar las medidas necesarias para la ejecución de la sentencia del Tribunal".

De acuerdo con la redacción originaria del Tratado de Roma, la única vía de actuación existente en el caso de que un Estado miembro se negase a cumplir con la obligación de dar cumplimiento a las sentencias del Tribunal de Justicia era la de interponer un nuevo recurso de incumplimiento, fundado en un incumplimiento de la obligación de ejecución impuesta por el art. 171 TCEE (actual art. 258 TFUE).

La proliferación de los recursos por incumplimiento del art.171 TCEE y el aumento del número de sentencias pendientes de cumplimiento generaron una corriente de opinión favorable a dotar a las instituciones de la Unión de vías coercitivas de ejecución de las sentencias del Tribunal de Justicia. Así, a impulso de la Comisión y de la delegación británica en la Conferencia Intergubernamental negociadora del Tratado de Maastricht ${ }^{2}$, se introdujo en el apartado 2 del art. 171 TCE lo que el Abogado General Mischo denominó más tarde un "recurso por no ejecución de una sentencia", en virtud del cual se facultaba al Tribunal de Justicia para imponer una multa coercitiva o una suma a tanto alzado al Estado miembro que no ejecutara una sentencia en la que se hubiera declarado su incumplimiento ${ }^{4}$. En las siguientes páginas nos ocuparemos del recurso por inejecución de sentencia.

${ }^{2}$ Unión Europea. Resolución sobre los resultados de las Conferencias Intergubernamentales. Diario Oficial de las Comunidades Europeas. C 125, 18 de mayo de 1992, p. 84.

${ }^{3}$ Conclusiones del Abogado General Mischo presentadas el 12 de junio de 2003 en el asunto Comisión/España, C-278/01, apartado 30.

${ }^{4}$ En relación con el recurso por inejecución de sentencia ver, con carácter general: M. J. BARCELÓ, Lecciones de derecho de la Unión Europea, Dir. Víctor M. SÁNchez, Bosch Internacional, Barcelona, 2008, pp. 245-256; M. MuÑoz Pérez, A. Rubio González y Abogados del Estado, "Capítulo IX: El recurso de incumplimiento", Procedimientos Administrativos y Fudiciales de la Unión Europea, Economist \& Jurist Difusión Jurídica, Madrid, 2012, pp. 455-587; M. Gómez de Liaño Fonseca, "La garantía jurisdiccional del Derecho Comunitario...”, cit.; B. JACK, "Article 260.2 TFEU: An Effective Judicial Procedure for the Enforcement of Judgements?", European Law Fournal, Vol. 19, n ${ }^{\circ} 3$, 2013, pp. 404-421; P. ANDrÉs Sáenz de SANTa María, "Primera multa coercitiva a un Estado miembro por inejecución de sentencia (Comentario a la STJCE de 4 de julio de 2000, Comisión/Grecia)", Revista de Derecho Comunitario Europeo, nº 8, (2000), pp. 493-518; J. DíEz-Hochleitner, "La respuesta del TUE al incumplimiento de Sentencias del Tribunal de Justicia por los Estados 


\section{EL PROCEDIMIENTO POR INCUMPLIMIENTO DE LA OBLIGACIÓN DE ADOPTAR LAS MEDIDAS NEGESARIAS PARA LA EJEGUCIÓN DE LA SENTENGIA}

\section{Legitimación de las partes}

En cuanto a la legitimación activa, solo la Comisión Europea puede, tras la tramitación de la fase precontenciosa previa, demandar al Estado miembro que incumpla la obligación de dar efecto a las sentencias del TJUE. Así lo dispone el art. 260.2 TFUE, cuya interpretación literal llevaría a negar a un Estado miembro, al BCE o al BEI el acceso a este mecanismo incluso cuando la sentencia hubiera sido dictada como consecuencia de un recurso por incumplimiento interpuesto por ellos mismos ${ }^{5}$. Por tanto, la única vía que quedaría para este Estado demandante en primera instancia sería volver a interponer un nuevo recurso por incumplimiento, en este caso por incumplimiento de sentencia, o instar a la Comisión a que ejercitase los poderes que se le reconocen en este ámbito ${ }^{6}$.

De otro modo, si se admitiera que un Estado miembro pudiera acudir a la vía del art. 260.2 TFUE surgirían dudas sobre la articulación exacta de la fase precontenciosa, sobre todo en cuanto a su forma y, en particular, sobre su carácter bilateral (afectando únicamente a los dos Estados miembros implicados) o trilateral (incluyendo también a la Comisión) ${ }^{7}$.

\section{Objeto del recurso por inejecución de sentencia}

El TJUE ha reconocido en diversas sentencias que el objeto del procedimiento del art.260 TFUE, apartado 2, no es otro que el de "inducir a un Estado infractor a ejecutar una sentencia dictada en un procedimiento por incumplimiento y, por ende,

miembros", RIE, no 3, 1993, pp. 837-900; A. SÁnchez LEGIDO, "El sistema judicial comunitario", cit. y T. Fajardo del Castillo, "Primera multa coercitiva a España en aplicación del procedimiento del artículo 228.2 del TCE: Comentario a la sentencia del TJCE de 25 de noviembre de 2003, asunto G-278/01, Comisión contra España”, RGDE, nº, (2004), pp. 1-24.

${ }^{5}$ En virtud del art. 259 TFUE, los Estados miembros están habilitados para interponer un recurso por incumplimiento contra otro Estado miembro ante el TJUE. También ostentan legitimación activa para interponer un recurso por incumplimiento (en casos excepcionales) el BCE y el BEI en virtud del art. 271.d) TFUE.

${ }^{6}$ A. SÁnchez Legido, "El sistema judicial comunitario"... cit. p.302.

${ }^{7}$ M. Rebollo Puig y A. Bueno ARmijo. "Administrative procedures prior to the action for failure to fulfil an obligation", Parlamento Europeo, Bruselas, 2011 (PE-432-765), disponible en http://www.europarl.europa.eu/studies, p. 16. Edición española publicada en Mercedes FuerTEs LóPEZ (coord.), Un procedimiento administrativo para Europa, Aranzadi, 2012, pp. 339-368. 
garantizar la aplicación efectiva del derecho comunitario"8, aunque también ha reconocido que las medidas que se pueden imponer deben dirigirse a "prevenir la repetición de infracciones análogas del Derecho comunitario"9. En definitiva, la clave para entender el procedimiento del artículo 260.2 TFUE es determinar cuáles son las consecuencias que pueden extraerse de una sentencia que declara el incumplimiento de un Estado miembro con arreglo al artículo 258 TFUE.

Por otra parte, el TJUE ha declarado que el objeto de este recurso por falta de ejecución de una sentencia queda circunscrito por el procedimiento precontencioso previo, en el sentido de que la Comisión, en su escrito de demanda, no puede ampliar el objeto del litigio invocando nuevos reproches respecto de los enunciados en el dictamen motivado en el que precisó los aspectos concretos en que el Estado miembro no cumplió la sentencia del TJUE por la que se declara el incumplimiento.

\section{Fase precontenciosa}

La interposición de una demanda al amparo del artículo 260 TFUE debe ir precedida de la tramitación por parte de la Comisión de una fase precontenciosa, cuya estructura concreta ha evolucionado a lo largo del tiempo. El procedimiento por incumplimiento de la obligación de adoptar las medidas necesarias para la ejecución de una sentencia declarativa de incumplimiento por parte de un Estado miembro fue regulado, en un primer momento, por el artículo 171.2 TCE (posterior artículo 228.2 TCE $)^{10}$, mientras que en la actualidad dicha regulación la encontramos en el art. 260 TFUE $^{11}$. Con la nueva redacción introducida por el Tratado de Lisboa ha quedado

${ }^{8}$ STJUE de 12 de julio de 2005, Comisión/Francia, C-304/02, apartado 80. También la Comisión declaraba en la Comunicación 96/C 242/07, de 21 de agosto de 1996, que la determinación del importe de la suma a tanto alzado o de la multa coercitiva debe estar guiada por el objetivo mismo de dicho instrumento, asegurar la aplicación efectiva del Derecho Comunitario.

${ }^{9}$ STJUE de 12 de julio de 2005, Comisión/Francia, C-304-02, apartado 80.

${ }^{10}$ Art. 171.2 TCE: "Si la Comisión estimare que el Estado miembro afectado no ha tomado tales medidas [para ejecutar una sentencia declarativa de incumplimiento], emitirá, tras haber dado al mencionado Estado la posibilidad de presentar sus observaciones, un dictamen motivado que precise los aspectos concretos en que el Estado miembro afectado no ha cumplido la sentencia del Tribunal de Justicia. Si el Estado miembro afectado no hubiere tomado las medidas que entrañe la ejecución de la sentencia del Tribunal en el plazo establecido por la Comisión, esta podrá someter el asunto al Tribunal de Justicia".

11 "Si la Comisión estimare que el Estado miembro afectado no ha adoptado las medidas necesarias para la ejecución de la sentencia del Tribunal, podrá someter el asunto al Tribunal de Justicia de la Unión Europea, después de haber ofrecido a dicho Estado la posibilidad de presentar sus observaciones. La Comisión indicará el importe de la suma a tanto alzado o de la multa coercitiva que deba ser pagada por el Estado miembro afectado y que considere adaptado a las circunstancias. Si el Tribunal 
suprimida una de las dos etapas de la fase precontenciosa, de modo que el requerimiento previo y el dictamen motivado posterior han quedado reducidos al "ofrecimiento al Estado para presentar observaciones". El propio TJUE señala que, "como resulta del propio texto del art. 260.2 TFUE, esta disposición ha modificado el desarrollo del procedimiento administrativo previo al suprimir la fase de emisión de un dictamen motivado. En lo sucesivo ese procedimiento solo tiene una fase, a saber, la de requerimiento al Estado miembro interesado" 12 .

No obstante, entendemos que, pese a que el tenor literal del artículo ha sido modificado, no ha habido un verdadero cambio material ya que antes de que el Estado presente sus observaciones habrá sido necesario que la Comisión haya formalizado en dicho requerimiento los presupuestos de hecho y de derecho que constituyen su acusación de incumplimiento, lo que constituía el contenido del dictamen motivado que hasta ahora se exigía expresamente. De otro modo, no es posible garantizar un derecho de defensa real al Estado supuestamente infractor, lo que sería, justamente, el objeto de esta fase precontenciosa. En este sentido ha determinado el TJUE que "el objetivo del procedimiento administrativo previo previsto en el artículo 260.2 TFUE es dar al Estado miembro interesado la ocasión de cumplir sus obligaciones derivadas del Derecho comunitario o de formular adecuadamente las alegaciones en su defensa frente a las imputaciones de la Comisión sobre la persistencia del incumplimiento"13.

\section{Fase jurisdiccional}

Como señaló el TJUE y puntualiza el Abogado General MAZAK en relación con el art. 260 TFUE, la fecha de referencia para apreciar la persistencia de un incumplimiento con arreglo al art. 228 TCE (actual art. 258 TFUE) se sitúa al expirar el plazo señalado en el dictamen motivado (ahora escrito de requerimiento) emitido en virtud de esta disposición ${ }^{14}$.

declarare que el Estado miembro afectado ha incumplido su sentencia, podrá imponerle el pago de una suma a tanto alzado o de una multa coercitiva. Este procedimiento se entenderá sin perjuicio de lo dispuesto en el artículo 259".

12 STJUE de 11 de diciembre de 2012, Comisión/España, C-610/10, apartado 43. En esta sentencia se imponen una multa coercitiva y una suma a tanto alzado al Reino de España por no haber dado ejecución a una sentencia anterior en la que se declaraba el incumplimiento de España de las obligaciones que le incumbían en virtud de la Decisión 91 / / CEE, de 20 de diciembre de 1989, relativa a las ayudas concedidas por el Gobierno español y los Consejos de gobierno de varias Comunidades Autónomas a Magefesa.

13 STJUE de 10 de septiembre de 2009, Comisión/Portugal, C-457/07, apartados 67 y 68.

${ }^{14}$ STJUE de 12 de julio de 2005, Comisión/Francia, C-304/02, apartado 30. En las Conclusiones presentadas por el Abogado General MAZAK el 6 de septiembre de 2012 en el asunto Comi- 
Por otra parte y respecto a la extensión del plazo marcado por la Comisión al Estado en la fase precontenciosa, parece que el TJUE no entra en ningún caso a valorar su adecuación u oportunidad. Y ello a pesar de la práctica adoptada por la Comisión de conceder siempre y en todo caso un plazo de dos meses ${ }^{15}$, lo cual dista mucho de seguir la jurisprudencia del TJUE sobre la "adaptación y la proporcionalidad a las circunstancias de cada caso".

La mayor peculiaridad en la interposición del recurso es la que se establece en el artículo 260.2 TFUE cuando indica que "La Comisión indicará el importe de la suma a tanto alzado o de la multa coercitiva que deba ser pagada por el Estado miembro afectado y que se considere adaptado a las circunstancias". Lo que no aclara el precepto es en qué momento la Comisión debe hacer esa indicación: si por primera vez en la demanda o antes, en la fase precontenciosa. Sería razonable pensar, a la luz de la jurisprudencia existente sobre el respeto a los derechos de defensa del Estado miembro supuestamente infractor, que la Comisión viene obligada a suministrar esa información al Estado miembro ya en la fase precontenciosa. Así se refuerza además el carácter persuasivo de estas medidas y se facilita la resolución de controversias sin necesidad de llegar a la fase contenciosa ${ }^{16}$. No obstante, tanto en la STJUE de 4 de julio de 2000 Comisión/Grecia, como en la STJUE de 25 de noviembre de 2003 Comisión/España y en las sucesivas, no es hasta la demanda ante el TJUE cuando la Comisión especifica el importe de la multa coercitiva o de la suma a tanto alzado.

\section{LA MULTA COERGITIVA Y LA SUMA A TANTO ALZADO}

Es conveniente partir del concepto y diferencias entre estas dos medidas en el ordenamiento español para observar las diferencias con el ordenamiento europeo. El Tribunal Constitucional, en su sentencia 239/1988, de 14 de diciembre, define la multa coercitiva como una "medida de constreñimiento económico, adoptada previo el oportuno apercibimiento, reiterada en lapsos de tiempo y tendente a obtener la

sión/España, C-610/10, apartado 40 señala que "Una vez suprimida la fase del dictamen motivado [se sustituye por el ofrecimiento al Estado para presentar observaciones], la fecha de referencia para apreciar la existencia de un incumplimiento en el sentido del artículo 260 TFUE, apartado 2, debería situarse, por analogía con la jurisprudencia relativa al artículo $228 \mathrm{CE}$, apartado 2, al término del plazo fijado por el escrito de requerimiento, o en su caso por el escrito de requerimiento complementario, para presentar las observaciones del Estado miembro interesado".

15 STUJE de 4 de julio de 2000, Comisión/Grecia, C-387/97; STJUE de 25 de noviembre de 2003, Comisión/España, C-278/01; STJUE de 12 de julio de 2015, Comisión/Francia, C-304/02; STUJE de 18 de julio de 2006, Comisión/Italia, C-119/04, etc.

${ }^{16}$ M. Rebollo Puig y A. Bueno Armijo, "Administrative procedures prior to the action for failure to fulfil an obligation", cit. p. 16. 
acomodación de un comportamiento obstativo del destinatario del acto a lo dispuesto en la decisión administrativa previa”. En cuanto a las diferencias con la sanción, doctrina y jurisprudencia se han encargado de apuntarlas, remarcando que la multa coercitiva no tiene un verdadero sentido sancionador y que carece de la finalidad represiva, retributiva o de castigo que el Tribunal Constitucional ha destacado como específica de las sanciones. La multa coercitiva no impone la obligación de pago con un fin represivo por la realización de una conducta ilícita, sino que la medida de constreñimiento económico en que consiste la multa coercitiva tiende a un fin completamente distinto y ya mencionado: "obtener la acomodación de un comportamiento obstativo del destinatario del acto a lo dispuesto en la decisión administrativa previa", forzar el cumplimiento ordenado ${ }^{17}$.

\section{La colaboración de la Gomisión en la interpretación y aplicación de la suma a tanto alzado y la multa coercitiva}

El TFUE no fija los criterios que deben ser tenidos en cuenta en el cálculo de la multa coercitiva y la suma a tanto alzado, otorgando a la Comisión un amplio margen discrecional en su propuesta. Por ello, la propia Comisión trató desde muy pronto de colmar esa laguna, reforzando el principio de seguridad jurídica a favor de los Estados miembros, mediante la publicación de Comunicaciones sobre la aplicación del antiguo artículo 171 TCE y sobre el cálculo de la multa coercitiva y la suma a tanto alzado.

Estas Comunicaciones de la Comisión forman parte del llamado softlaw de la Unión, término con el que se pretende aludir a «un fenómeno que presenta las características del "Derecho" en cuanto a su pretendido efecto de influenciar en el deseo y de restringir la libertad de aquellos a quien el softlaw se dirige», pero que al ser mencionado produce la sensación de que «algo falta en la naturaleza jurídica o vinculante del Derecho tal y como lo conocemos en la vida cotidiana» ${ }^{18}$. Parece que estas Comunicaciones están destinadas esencialmente a presidir ad intra el funcionamiento del aparato institucional de la Unión y a sentar, en su caso, reglas de juego interinstitucionales. En este caso la Comisión trata de dar, mediante estas Comunicaciones, unas directrices sobre cuál será su proceder acerca de las propuestas de multas coercitivas y sumas a tanto alzado que proponga al TJUE en caso de que los Estados miembros no tomen las medidas necesarias para ejecutar las sentencias de-

${ }^{17}$ R. Pizarro Nevado, "La multa coercitiva”, Revista del Poder Fudicial, G.G.P.J, no 62, 2001, p. 377.

18 Tammes, "Soft Law", International and Comparative Law in Honour of Fudge Erades, Martinus Nihoff Publisher, 1983, p.187. Apud. R. Alonso García, "El softlaw comunitario", Revista de Administración Pública n 154, 2001, p. 64. 
clarativas de incumplimiento. Como se expondrá posteriormente, el propio TJUE señala en su jurisprudencia que estas Comunicaciones no le vinculan. Sin embargo, el hecho de que el softlaw en general y las Comunicaciones en particular no tengan efectos vinculantes frente a terceros no implica per se que no tengan efectos jurídicos. Piénsese, por ejemplo, en la posible entrada en juego de principios como el de venire contra factum proprium non valet o el de protección de la confianza legítima, que impedirían a las Instituciones de la Unión apartarse sin más del marco de referencia establecido vía softlaw ${ }^{19}$.

La práctica de la Comisión durante los primeros años de aplicación de este procedimiento consistió en proponer al TJUE exclusivamente la imposición de multas coercitivas y no sumas a tanto alzado. Sin embargo, dicha práctica cambió sustancialmente a partir de la STJUE de 12 de julio de 2005, Comisión/Francia, C-304/02, en la que el Tribunal, a pesar de que la Comisión no había solicitado la imposición de una suma a tanto alzado, admitió por primera vez de forma expresa la posibilidad de que ambas medidas se impusieran simultáneamente. A consecuencia de dicha sentencia, la Comisión adoptó el 13 de diciembre de 2005 una nueva Comunicación sobre la aplicación del artículo 228 TCE que sustituyó a las anteriore ${ }^{20}$.

En dicha Comunicación, la Comisión reconoce que la multa coercitiva es, aparentemente, el instrumento más adecuado para lograr el objetivo de la efectiva aplicación del Derecho de la Unión. Sin embargo, razona que su práctica tradicional de solicitar únicamente la imposición de ese "tipo de sanción" (sic) daba lugar a que en aquellos supuestos en los que la completa ejecución de la primera sentencia de incumplimiento se producía antes de que el Tribunal dictase la segunda condena, la conducta del Estado miembro infractor quedaba "sin sanción" (sic), sin importar cuánto tiempo había tardado en dar cumplimiento a la sentencia del TJUE ${ }^{21}$. Por ello se anunciaba que, en las demandas interpuestas al amparo del artículo 260.2 TFUE a partir del 1 de enero de 2006, la Comisión, como regla general, solicitaría siempre la imposición de ambos tipos de "sanción pecuniaria" (sic).

${ }^{19}$ R. Alonso García, "El softlaw comunitario", cit., p. 84.

${ }^{20}$ Comunicación de la Comisión SEG (2005) 1658; DO C 126 de 7.6.2007, p. 15.

${ }^{21}$ Como resume B. JACK en "Article 260.2 TFEU: An Effective Judicial Procedure for the Enforcement of Judgements?", cit. p. 409: "Poniendo el foco en el cumplimiento futuro en lugar de en la culpa del pasado, ni siquiera se impondrá multa coercitiva cuando un Estado miembro cumple tardíamente con el juicio iniciado contra él. Se podría argumentar que esto es totalmente acorde con el papel coercitivo de las multas coercitivas pues el objetivo último ha sido cumplido. Sin embargo esto permite que los Estados miembros retrasen los cumplimientos sistemáticamente. De hecho, se ha demostrado que estos retrasos se han incrementado. Por ello, la Comisión ha tratado de utilizar la suma a tanto alzado para evitar dichos retrasos sistemáticos sin penalización.” 


\section{La no vinculación del TJUE a la propuesta de la Comisión}

En el seno del proceso del art. 260.2 TFUE, el TJUE goza de una jurisdicción plena. Ello quiere decir que podrá acordar estas condenas pecuniarias aunque no las haya pedido la Comisión o, cuando lo haya hecho, en mayor o en menor cuantía a lo solicitado por esta. Sirva como ejemplo la STJUE de 4 de julio de 2000, Comisión/Grecia, C-387/97, en la que el TJUE, además de confirmar el carácter no vinculante de las propuestas de la Comisión ${ }^{22}$, impuso una multa coercitiva de menor importe que la que había propuesto esta. Respecto a la suma a tanto alzado, en la STJUE de 17 de octubre de 2013, Comisión/Bélgica, C-533/11, el TJUE señaló que el art.260 TFUE confiere al propio Tribunal una amplia facultad de apreciación para decidir si procede o no imponer tal "sanción" y determinar, en su caso, su importe. Así mismo añadió que "las propuestas de la Comisión no pueden vincular al Tribunal y no constituyen sino indicaciones. Del mismo modo, las directrices en materia de condena al pago de sumas a tanto alzado, como las que figuran en la Comunicación SEG (2005) 1658 [...], no vinculan al TJUE, si bien pueden contribuir a garantizar la transparencia, la previsibilidad y la seguridad jurídica de la actuación de la Comisión".

En referencia a esta cuestión, el art. 260.2 TFUE ha sido criticado por ciertos autores. Según M. BacigaluPo SAGgese, el TFUE otorga a la Comisión y al Tribunal una discrecionalidad excesiva difícilmente compatible con el principio de legalidad que rige la imposición de penas y sanciones en los Estados de Derecho, sin perjuicio de lo que luego se dirá respecto al carácter sancionador o no de estas medidas. El mismo autor sostiene que el TJUE debería observar, al menos, el principio ne ultra petitum, por lo que no debería en ningún caso rebasar o desbordar la propuesta formulada por la Comisión ${ }^{23}$.

\section{La multa coercitiva y la suma a tanto alzado como medi- das de ejecución, la cuestionada doble imposición}

Hasta la STJUE de 12 de julio de 2005, Comisión/Francia, C-304/02, la medida contra el Estado incumplidor había consistido en una multa coercitiva que, depen-

${ }^{22}$ Admite el TJUE que "la Comisión puede adoptar directrices cuyo objetivo sea establecer los criterios para calcular el importe de las sumas a tanto alzado o de las multas coercitivas que decida proponer al TJUE", pero añade que "estas propuestas de la Comisión no pueden vincular al Tribunal de Justicia" (apartados 84 y 89 de la Sentencia).

${ }^{23}$ M. Bacigalupo SAggese, "El sistema jurisdiccional de la Unión Europea", cit. p. 544. 
diendo de las circunstancias de cada caso, variaba en cuantía, periodicidad y permanencia. Sin embargo, a partir de la citada sentencia se contempla la posibilidad de imponer al Estado incumplidor una multa coercitiva y una suma a tanto alzado simultáneamente ${ }^{24}$.

La pasividad de Francia para aplicar los Reglamentos relativos al control de la pesca, para incoar procedimientos frente a sus ciudadanos incumplidores así como la duración del incumplimiento parece que hicieron sopesar al TJUE la posibilidad de incluir la suma a tanto alzado como medida para forzar el cumplimiento. En efecto, señala el TJUE en la citada sentencia que "La obligación de los Estados miembros de velar por que las infracciones de la normativa comunitaria sean objeto de sanciones efectivas, proporcionadas y disuasorias reviste una importancia esencial en el ámbito de la pesca"25. Así podríamos interpretar que lo que Francia no hizo respecto a sus administrados (hacer cumplir los Reglamentos), lo hizo el TJUE con la República francesa ya que "Si las autoridades competentes de un Estado se abstuvieran sistemáticamente de ejercitar acciones de esta índole contra los responsables de dichas infracciones, correrían grave peligro tanto la conservación y la gestión de los recursos pesqueros como la ejecución uniforme de la política pesquera común"26.

Este reforzamiento del procedimiento de ejecución de sentencias con la suma a tanto alzado fue objeto de consulta por parte del TJUE a los países de la UE coadyuvantes en el procedimiento contra Francia, los cuales dieron argumentos a favor y en contra de la medida. Entre los argumentos a favor ${ }^{27}$ se destacó que "la combinación de estas medidas debe ser considerada un mismo medio para alcanzar el objetivo establecido en el artículo 228 TCE, es decir, no solo inducir al Estado miembro afectado a cumplir la sentencia inicial, sino también, desde un punto de vista más general, reducir la posibilidad de que se cometan infracciones análogas". Entre los argumentos en contra ${ }^{28}$ podemos destacar la consideración de que la acumulación de

${ }^{24}$ En el mismo sentido se han expresado también las posteriores STJUE de 16 de diciembre de 2012 Comisión/Irlanda, C-374/11; STJUE de 28 de noviembre de 2013, Comisión/Luxemburgo, G576/11; STJUE de 2 de diciembre de 2014, Comisión/Italia, C-196/13; STJUE de 4 de diciembre de 2014, Comisión/Suecia, C-243/13 y STJUE de 16 de julio de 2015, Comisión/Italia, C-653/13 entre otras.

${ }^{25}$ STJUE de 12 de julio de 2005, Comisión/Francia, C-304/02, apartado 69.

26 STJUE de 12 de julio de 2005, Comisión/Francia, C-304/02, apartado 69.

${ }^{27}$ Esgrimidos por la parte demandante (Comisión) y Estados miembros coadyuvantes (Gobiernos danés, neerlandés, finlandés y del Reino Unido).

${ }^{28}$ Esgrimidos por el Estado miembro demandado (Gobierno francés) y Estados coadyuvantes (gobiernos belga, checo, alemán, helénico, español, irlandés, italiano, chipriota, húngaro, austriaco, polaco y portugués). 
"sanciones" pecuniarias por un mismo hecho sería contraria al principio ne bis in idem; por otra parte, se esgrimía la vulneración de los principios de transparencia y seguridad jurídica por no existir directrices de la Comisión respecto a la suma a tanto alzado; por último, también se criticaba la vulneración de los principios de igualdad de trato respecto a otros países por no haberse utilizado esta medida contra Grecia o España (países también condenados en anteriores pronunciamientos por no ejecutar sus respectivas sentencias declarativas de incumplimiento $)^{29}$.

Como respuesta, el TJUE trata de explicar la diferencia entre una y otra medida y la justificación de su utilización simultánea para después rechazar uno a uno los argumentos en contra esgrimidos por los Estados miembros.

En primer lugar, señala que, pese a que las dos medidas tienen el objetivo de "inducir a un Estado miembro infractor a ejecutar una sentencia dictada en un procedimiento por incumplimiento y, por ende, garantizar la aplicación efectiva del derecho comunitario" 30 , su fundamento es distinto ya que "si la imposición de una multa coercitiva resulta especialmente adaptada para inducir a un Estado miembro a poner fin lo antes posible a un incumplimiento que, de no existir esta medida, tendría tendencia a persistir, la imposición del pago de una suma a tanto alzado descansa más bien en la apreciación de las consecuencias del incumplimiento de las obligaciones del Estado afectado en los intereses privados y públicos, en especial cuando el incumplimiento se ha mantenido largo tiempo después de la sentencia que inicialmente lo declaró" 31 . En definitiva, la suma a tanto alzado se convierte, principalmente, en un vehículo para sancionar la demora ${ }^{32}$.

Siguiendo con la respuesta del TJUE a los argumentos de los países que estaban en contra de utilizar las dos medidas simultáneamente, mediante una argumentación poco convincente determina que, pese a que el art. 228.2 TCE utiliza la conjunción "o" para unir las "sanciones" pecuniarias que pueden imponerse, dicha conjunción tiene un sentido acumulativo o alternativo y que, por tanto, es posible decantarse por el sentido acumulativo. En segundo lugar, rechaza la vulneración de ne bis in idem ya que, como se ha explicado, cada medida tiene un fundamento distinto y para vulnerar este principio es necesaria la coincidencia de sujeto, hecho y fundamento. De ello cabría deducir que el TJUE interpretó que ambas medidas tienen naturaleza sancionadora y que lo único que la diferencia es el fundamento, pero sobre el debate rela-

${ }^{29}$ STJUE de 12 de julio de 2005, Comisión/Francia, C- 304/02, apartado 79.

${ }^{30}$ Apartado 80 de STJUE de la misma sentencia.

31 Apartado 81 de la misma sentencia.

${ }^{32}$ B. JACK en "Article 260.2 TFEU: An Effective Judicial Procedure for the Enforcement of Judgements?", cit. p. 414. 
tivo a la naturaleza jurídica de estas medidas volveremos más adelante. Por último y en tercer lugar, el TJUE señala que el ejercicio de la facultad que el art. 228.2 TCE (actual art. 260.2 TFUE) confiere al Tribunal no está sujeto al requisito de que la Comisión adopte directrices acerca de la suma a tanto alzado que, además, no vincularían al TJUE. Respecto a la vulneración del principio de igualdad de trato entre Estados miembros incumplidores, el TJUE recuerda su competencia para apreciar, en cada asunto y teniendo en cuenta sus características específicas, las medidas que procede imponer. El margen de apreciación del tribunal llega a tal punto en este caso que, sin que la Comisión hubiese solicitado la imposición de la suma a tanto alzado, el TJUE decide de forma autónoma utilizar las dos medidas de forma simultánea.

\section{El confuso debate sobre la naturaleza sancionadora o no de estas medidas}

Tras aquella pionera sentencia en la que se impusieron simultáneamente las dos medidas previstas en el art. 260 TFUE se reabrió el interesante debate sobre la naturaleza de tales medidas. Según el TJUE, nos encontrábamos ante "un proceso judicial que debe entenderse como un peculiar trámite judicial de ejecución de sentencias, es decir, un procedimiento de ejecución"33. Dicho en otros términos, se negaba su naturaleza sancionadora. En este sentido, la mejor muestra de que la multa coercitiva y la suma a tanto alzado tenían como finalidad la ejecución de la previa sentencia de incumplimiento y no una finalidad sancionadora era que, aún cuando el incumplimiento persistía una vez expirado el plazo determinado por la Comisión, si cuando se producía el análisis de los hechos por parte del TJUE el incumplimiento había cesado, este optaba por no imponer el pago de las medidas pecuniarias y únicamente declaraba que el cumplimiento no se produjo en el plazo establecido. Este fue el caso de la STJUE de 18 de julio de 2006, Comisión/Italia ${ }^{34}$ y de la STJUE de 18 de julio de 2007, Comisión/Alemania ${ }^{35}$. La conclusión que podemos extraer es que

33 STJUE de 12 de julio de 2005, Comisión/Francia, C-304/02, apartado 91.

${ }^{34}$ En la STJUE de 18 de julio de 2006, Comisión/Italia, C-119/04, se juzgaba si Italia había ejecutado la sentencia declarativa de incumplimiento que la condenaba. Pese a que el cumplimiento fue extemporáneo, dado que "no existían suficientes elementos que permitieran al Tribunal de Justicia concluir que el incumplimiento persiste en la fecha de examen de los hechos" el TJUE optó por la no imposición de multa coercitiva ni suma a tanto alzado (apartados 45 y 46 de la sentencia).

35 STJUE de 18 de julio de 2007, Comisión/Alemania, C-503/04: La República alemana había incumplido una Directiva sobre contratación pública en la formulación de dos contratos en los municipios de Bockhorn y Brunswick. Ello provocó una sentencia declarativa de incumplimiento el 10 de abril de 2003, la cual fue objeto de un recurso por inejecución al estar vigentes tales contratos hasta 2005. Sin embargo, en el momento de análisis de los hechos por parte del TJUE en el seno del recurso por inejecución de sentencia, uno de esos contratos había sido anulado y el otro resuelto, por lo que en esta sentencia de 2007 el Tribunal se limitó a declarar el cumplimiento extemporáneo de la sentencia de 2003 pero no impuso ninguna medida pecuniaria. 
la finalidad de la multa coercitiva o la suma a tanto alzado no era represiva en su concepción original, porque si fuera así serían impuestas por el TJUE para castigar un pasado incumplidor. Dado que la finalidad era evitar que persistiera el incumplimiento en el futuro, una vez que este cesaba ya no tenía sentido mantenerlas.

En el año 2008, sin embargo, hay un cambio de rumbo en la concepción de la suma a tanto alzado y el TJUE parece replantearse la posibilidad de que, pese a haber sido ejecutada una sentencia en fase jurisdiccional del procedimiento, tenga sentido mantener las medidas de ejecución o, al menos, una de ellas (suma a tanto alzado). Ello nos permite intuir, además del distinto fundamento ya apreciado por el TJUE, la diferente naturaleza de la multa coercitiva y la suma a tanto alzado.

La sentencia de 9 de diciembre de 2008, Comisión/Francia, asunto C-121/07 presenta la especialidad de que el Estado miembro demandado, Francia, ejecuta la sentencia declarativa de incumplimiento ${ }^{36}$ una vez expirado el plazo otorgado por la Comisión en el dictamen motivado de la fase precontenciosa, es decir, durante el procedimiento judicial. Es por eso que el TJUE se ve obligado a determinar la finalidad de cada una de las medidas de ejecución y su mantenimiento.

Sobre la multa coercitiva señala el tribunal que "en principio solo está justificada en la medida en que perdure el incumplimiento basado en la falta de dar ejecución a una sentencia anterior del Tribunal de Justicia", por ello "a la luz de lo anterior, el Tribunal de Justicia considera que no ha lugar a la condena al pago de una multa coercitiva". Este razonamiento parece lógico, teniendo en cuenta que este tipo de medida tiene una naturaleza coercitiva con respecto al incumplimiento en curso; por tanto, si ha desaparecido el incumplimiento, debe desaparecer esta medida puesto que su causa misma habría desaparecido.

Respecto a la suma a tanto alzado, ya había adelantado la Comisión en su Comunicación de $2005^{37}$ que, en adelante, cuando interpusiera un recurso ante el Tribunal de Justicia en virtud del artículo 228 TCE (actual 260 TFUE), solicitaría sistemáticamente que se condenara al Estado miembro infractor al pago de una suma a tanto alzado y que mantendría dicha petición, sin desistir de su recurso, ni siquiera en caso de que durante el procedimiento se diera ejecución a la sentencia anterior del Tribunal de Justicia. Según la Comisión este nuevo enfoque estaría justificado para

36 STJUE de 15 de julio de 2004, Comisión/Francia, C-419/03, relativa a la no adaptación del Derecho interno francés a las disposiciones de la Directiva 2001/18/CE del Parlamento Europeo y del Consejo, de 12 de marzo de 2001, sobre la liberación internacional en el medio ambiente de organismos modificados genéticamente.

${ }^{37}$ Comunicación de la Comisión SEG (2005) 1658; DO C 126 de 7.6.2007, p. 15. 
evitar que se vulnerasen la fuerza obligatoria de las sentencias del Tribunal de Justicia, los principios de legalidad y seguridad jurídica y la eficacia del Derecho de la Unión. Además señalaba que el no imponer sanción económica alguna en caso de incumplimiento tardío durante el procedimiento suponía un riesgo de incitar a los Estados miembros a no ejecutar diligentemente las sentencias del Tribunal de Justicia y a adoptar sistemáticamente comportamientos dilatorios.

Respecto a este procedimiento concreto contra Francia, la Comisión recordó todos los procesos iniciados contra este Estado miembro en materia de incumplimiento del Derecho de la Unión (50 requerimientos, 125 dictámenes motivados, 6 recursos etc.), por lo que recalcaba que, a diferencia de la multa coercitiva, que tiene una función persuasiva en cuanto al incumplimiento en curso y que tiene por finalidad prevenir su persistencia después de que el Tribunal de Justicia haya dictado sentencia al amparo del artículo 260 TFUE, la suma a tanto alzado tiene más bien por objeto sancionar el comportamiento adoptado en el pasado. La Comisión defendía, pues, que la suma a tanto alzado tiene una finalidad disuasoria y preventiva en cuanto a la repetición de infracciones análogas.

Lo mismo entendió el Tribunal de Justicia, que hizo suya la opinión de la Comisión acerca de la diferente finalidad de estas dos medidas señalando que "si bien la condena de una multa coercitiva solo se impone en la medida en que perdure la inejecución de la sentencia en que inicialmente se declaró el incumplimiento, nada exige que lo mismo ocurra con la imposición del pago de una suma a tanto alzado". De este modo, el TJUE cambiaba su jurisprudencia respecto a la STJUE de 18 de julio de 2006, Comisión/Italia, C-119/04 y la STJUE de 18 de julio de 2007, Comisión/Alemania, C-503/04; sentencias en las que había decidido no interponer ninguna de las medidas ejecutivas tras el cumplimiento por parte del Estado en cuestión, declarando únicamente el cumplimiento extemporáneo.

A continuación el Tribunal entró a valorar las características del incumplimiento de Francia para justificar el mantenimiento de la suma a tanto alzado. En primer lugar el TJUE recordó que Francia ya había sido objeto de varias sentencias dictadas con arreglo al 226 TCE (actual art. 258 TFUE) en las que se declaraba su incumplimiento por no haber adaptado correctamente su Derecho interno a las Directivas adoptadas en este ámbito, "tal repetición de comportamientos ilícitos de un Estado miembro puede constituir un indicador de que la prevención efectiva de que en el futuro se repitan infracciones análogas del Derecho comunitario requiere la adopción de una medida disuasoria, como la imposición de una suma a tanto alzado". En segundo lugar, el Tribunal valoró que "nada permite justificar el gran retraso (casi 3 años) constatado en la adaptación efectiva del Derecho interno a la Directiva 2001/18 después de haber recaído la sentencia declarativa de incumplimiento". Por último y en tercer lugar el TJUE analizó la gravedad del incumplimiento valorando 
su influencia en los intereses públicos y privados, determinando que "cuando la no ejecución de una sentencia del TJUE puede perjudicar el medio ambiente y pone en peligro la salud humana cuya preservación forma parte de los propios objetivos de la política medioambiental de la Comunidad, como resulta del art. $174 \mathrm{CE}$, tal incumplimiento reviste especial gravedad". Por todo ello, se justificaba la imposición de la suma a tanto alzado incluso a pesar de que ya se había puesto fin a la situación de incumplimiento. Los argumentos del Tribunal de Justicia permiten concluir que tanto la gravedad de la infracción como su duración son tenidas en cuenta en la imposición de la multa coercitiva y la suma a tanto alzado. Como bien recuerda Sobrido PRIETO, "la consideración de los intereses públicos y privados afectados también sirve para determinar el coeficiente de gravedad a utilizar en el cálculo de las multas coercitivas"38.

Si recordamos, mientras que en la STJUE de 18 de julio de 2006, Comisión/Italia y en la STJUE de 18 de julio de 2007, Comisión/Alemania, la ejecución voluntaria (aunque extemporánea) del Estado incumplidor provocaba la ausencia total de imposición de medidas pecuniarias por parte del TJUE, esta sentencia de 2008 Comisión/Francia supone un cambio de rumbo por parte del órgano jurisdiccional, ya que, pese a que Francia ejecutó la sentencia antes de que el TJUE se pronunciara, ello no privó al Tribunal de mantener la suma a tanto alzado como "medida sancionadora"39.

Si era una medida que formaba parte de un "especial proceso de ejecución", como el mismo Tribunal de Justicia había declarado en anteriores pronunciamientos, no tenía sentido mantenerla una vez desaparecido su objeto. Así lo ha sostenido posteriormente la República Helénica en otra sentencia dirigida contra ella, argumentando que no procedía "imponerle el abono de una cantidad a tanto alzado, dada la finalidad disuasoria de la condena al pago de una cantidad a tanto alzado y habida cuenta de [...] que ya había realizado todos los actos necesarios para la plena ejecución de la sentencia declarativa de incumplimiento" 40 .

${ }^{38}$ M. SOBRIDO PRIETO, "Primera condena al pago simultáneo de una multa coercitiva y de una suma a tanto alzado por inejecución de sentencia. Comentario a la STJCE de 12 de julio de 2005, C-304/02, Comisión/Francia", RGDE, nº, (2006), p. 30.

${ }^{39}$ Esta jurisprudencia también es mantenida por el TJUE en la STJUE de 30 de mayo de 2013, Comisión/Suecia, C-270/11, la STUJE de 25 de junio de 2013, Comisión/República Checa, C-241/11 y la STJUE de 13 de mayo de 2014, Comisión/España, C-184/11.

40 STJUE de 2 de diciembre de 2004, Comisión/Grecia, G-378/13. En ella la República Helénica es condenada al pago de una suma a tanto alzado por no haber ejecutado en plazo la sentencia declarativa de incumplimiento de las obligaciones de la Directiva 75/442, en concreto "las medidas necesarias para garantizar que los residuos se valorizarán o se eliminarán sin poner en peligro la salud del hombre y sin utilizar procedimientos ni métodos que puedan perjudicar el medio ambiente". El hecho de que no existiera condena a multa coercitiva nos permite deducir que el Estado miembro ya había dado ejecución a la sentencia cuando se valoraron los hechos. 
En consecuencia, cabe deducir de la evolución jurisprudencial del TJ que la multa coercitiva y la suma a tanto no solo tienen un fundamento distinto, sino que también tienen una naturaleza distinta, pudiendo calificar la multa coercitiva como medida de ejecución y la suma a tanto alzado como medida de represión, disuasoria o incluso sancionadora. En cualquier caso, y en atención a lo expuesto, no cabe seguir manteniendo la naturaleza meramente ejecutiva de la suma a tanto alzado como el TJUE sigue haciendo en la STJUE de 15 de enero de 2014, Comisión/Portugal, G292/11 P, al calificar el procedimiento del artículo 260 TFUE como "un procedimiento judicial especial de ejecución de las sentencias del TJUE” (apartado 40). Quizás para comprender esta postura del Tribunal deberíamos acudir a la opinión que comparten los Abogados Generales KокотT y Jä̈sKInEN cuando afirman que "las sanciones encaminadas a obtener la ejecución de una sentencia son distintas de las sanciones represivas" ${ }^{\prime 1}$.

Tras lo analizado cabe traer a colación lo expuesto al principio de este epígrafe sobre la diferencia, en el ordenamiento español, entre la multa coercitiva y las sanciones. Si bien la multa coercitiva del TJUE se asimila mucho a la nacional, respecto a la suma a tanto alzado resulta más lógico asimilarla a una sanción, cuyos adjetivos calificativos (represiva, retributiva o de castigo) aportados por el Tribunal Constitucional la definen mejor que considerarla como parte de un "especial proceso de ejecución" como señala la jurisprudencia del TJUE. Partiendo de esta base sería extrapolable la opinión de R. Pizarro Nevado, que señala que la compatibilidad entre multas coercitivas y sanciones (suma a tanto alzado) se produce solo en los supuestos en que el ordenamiento jurídico asigna a un único comportamiento, el incumplimiento de una obligación impuesta por la Administración (en nuestro, caso ordenamiento jurídico europeo), una doble reacción: por una parte, la imposición de una sanción (suma a tanto alzado), en tanto ese comportamiento se encuentre tipificado como una infracción; y, por otra, la ejecución simultánea de la obligación incumplida a través de multas coercitivas ${ }^{42}$.

\section{Cálculo de la multa coercitiva}

El TJUE ha señalado que esta medida debe fijarse en función del grado de presión que fuere necesario para incitar al Estado miembro infractor a ejecutar una sentencia por incumplimiento y modificar su comportamiento para poner fin a la in-

${ }^{41}$ Conclusiones del Abogado General Nilo JüÄskinen presentadas el 16 de mayo de 2013, asunto C-292/11 P, apartado 84 y Conclusiones del Abogado General Juliane KoKOTT presentadas el 28 de enero de 2010, asunto C-526/08, apartado 33.

${ }^{42}$ R. Pizarro Nevado, "La multa coercitiva...", cit. p. 378. 
fracción reprochada ${ }^{43}$. Como señala SÁnchez RIVERA, "las multas coercitivas se implantan en la confianza de ser un medio para forzar la voluntad de un Estado contumaz, para que aplique finalmente lo establecido en la sentencia de incumplimiento"44.

En la Comunicación de la Comisión del año 2005 ${ }^{45}$, se establecen tres criterios generales de cálculo para la propuesta de multa coercitiva: la gravedad del incumplimiento, su duración y la necesidad de asegurarse de que la sanción tenga un efecto disuasorio de futuros incumplimientos. Además, se pretende garantizar el respeto a los principios de proporcionalidad e igualdad de trato a los Estados miembros.

La fórmula para el cálculo de la propuesta de multa coercitiva que la Comisión introdujo en su Comunicación de 2005 fue la siguiente ${ }^{46}$ :

$$
[\mathrm{Md}=(\mathrm{Tb} \times \mathrm{Cg} \times \mathrm{Cd}) \times \mathrm{n}]
$$

En donde $\mathrm{Md}=$ multa coercitiva diaria, $\mathrm{Tb}=$ tanto alzado de base, $\mathrm{Cg}=$ coeficiente de gravedad, $\mathrm{Cd}=$ coeficiente de duración, $\mathrm{n}=$ factor que tiene en cuenta la capacidad de pago del Estado en cuestión ${ }^{47}$.

Respecto al último de estos elementos, a raíz de la Comunicación de la Comisión 97/C 63/02 se fijaron el PIB de los Estados miembros y la ponderación de sus votos en el Consejo como criterios de cuantificación para valorar la capacidad de pago del Estado miembro. Al respecto nos parece lógica la crítica de R. SILVA LAPUERTA ${ }^{48}$, que no encuentra justificación a la utilización de la ponderación de votos en el Consejo para determinar la capacidad de pago del Estado miembro y considera que debe utilizarse el PIB corregido, en su caso, con la renta per cápita por habitante. Teniendo en cuenta que el número de votos de cada país en el Consejo depende de su población (aunque los números están ponderados en favor de los países con menor número de ciudadanos), no se comprende que el TJUE relacionara la población con la capacidad de pago de un país ${ }^{49}$.

\footnotetext{
${ }^{43}$ STJUE de 12 de julio de 2005, Comisión/Francia, C-304/02, apartado 91.

${ }^{44}$ P. SÁnchez Rivera, "Las multas coercitivas del Tribunal de Justicia de las Comunidades Europeas", Noticias de la Unión Europea n ${ }^{\circ} 294$ (2009), p.145.

${ }^{45}$ Comunicación de la Comisión SEC (2005) 1658; DO C 126 de 7.6.2007, p. 15.

${ }^{46}$ Fórmula asumida por el TJUE para sus resoluciones, independientemente de que el resultado sea distinto del de la Comisión al utilizar diferentes graduaciones de los conceptos.

${ }^{47}$ La última actualización de los factores de cálculo constantes la encontramos en la Comunicación de la Comisión (2015/C 257/01); DO C 257 de 6.8.2015, p. 1.

${ }^{48}$ R. SILVA DE LAPUERTA "La ejecución de las sentencias de incumplimiento por los Estados miembros", Noticias jurídicas de la Unión Europea, nº 178, 1999, p. 85.

49 Sirvan de ejemplo Luxemburgo, cuyo PIB es altísimo en comparación con su población, o España, que tiene 27 votos en el Consejo frente a 29 de Alemania, teniendo esta última casi el doble de población que España y un PIB mucho mayor. El absurdo es aún mayor si tenemos en cuenta que tras el Tratado de Lisboa se prevé la desaparición de la ponderación de votos en el Consejo.
} 


\section{Cálculo de la suma a tanto alzado}

Como ya se ha mencionado, a diferencia de lo que sucede en el caso de la multa coercitiva, el Tribunal ha declarado que la imposición de una suma a tanto alzado puede resultar oportuna aun en el caso de que el incumplimiento haya desaparecido en el momento en que el TJUE aprecie los hechos. Sin embargo no debe entenderse que la condena tenga carácter automático, sino que dependerá de un conjunto de elementos entre los que el Tribunal ha mencionado las características del incumplimiento declarado y el comportamiento del Estado miembro afectado ${ }^{50}$.

Como señaló la STJUE de 2 de diciembre de 2004, Comisión/Grecia, C- 378/13, las características del incumplimiento que resultan relevantes para acordar la condena al pago de una suma a tanto alzado son la duración del mismo, contada desde la fecha de la sentencia que lo declaró, así como su gravedad en relación con los intereses públicos y privados afectados ${ }^{51}$.

En cuanto a la actitud del Estado miembro, el Tribunal ha tomado en consideración el retraso en la contestación a los requerimientos de la Comisión en la fase precontenciosa del procedimiento ${ }^{52}$ o la existencia de otras sentencias de incumplimiento contra el mismo Estado en la misma materia" 53 , ya que "tal repetición de comportamientos ilícitos de un Estado miembro, en un sector específico de la acción comunitaria, puede constituir un indicador de que la prevención efectiva de que en el futuro se repitan infracciones análogas del Derecho comunitario requiere la adopción de una medida disuasoria, como la imposición de una suma a tanto alzado" 54 .

\section{Ejecución de la multa coercitiva y de la suma a tanto al- zado}

Dado que los Tratados no establecieron disposiciones relativas a la ejecución de las sentencias dictadas al amparo del artículo 260.2 TFUE, son dos los principales problemas que se plantean a la hora de liquidar estas medidas pecuniarias. Por una

50 STJUE de 11 de diciembre de 2012, Comisión/España, C-610/10.

${ }^{51}$ En este sentido, en la STJUE de 30 de mayo de 2013, Comisión/Suecia, C-270/11, el TJUE consideró especialmente grave el incumplimiento del estado miembro demandado en la medida en que la no transposición por el Reino de Suecia de la Directiva 2006/24 causó un perjuicio económico a empresas establecidas en toda la Unión y a otros Estados miembros (al mismo tiempo que confirió una ventaja a los operadores privados de telecomunicaciones suecos).

52 STJUE de 31 de marzo de 2011, Comisión/Grecia, C-407/09, apartado 33.

53 STJUE de 17 de noviembre de 2011, Comisión/Italia, C-496/09, apartado 91.

${ }^{54}$ STJUE de 9 de diciembre de 2008, Comisión/Francia, C-121/07, apartado 69 y STJUE de 13 de mayo de 2014, Comisión/España, G-184/11, apartado 78. 
parte, se cuestiona si corresponde a la Comisión la competencia para ejecutar estas medidas, y por otra parte, y una vez aceptada dicha competencia, se discute su alcance a la hora de verificar el completo cumplimiento de las obligaciones del Estado miembro.

Respecto al primero de los problemas, una vez que el TJUE ha dictado una sentencia que declara la falta de ejecución de su previa sentencia de incumplimiento e impone una suma a tanto alzado o una multa coercitiva o ambas, el Estado miembro condenado debe proceder al abono de la correspondiente suma a la Comisión Europea en la cuenta "Recursos propios de la Unión Europea". Francia fue el primer Estado miembro en cuestionar la competencia recaudatoria de la Comisión ${ }^{55}$, es decir, su capacidad para declarar el devengo y liquidar dichas cantidades. Sin embargo, la jurisprudencia del Tribunal General señaló al respecto que la Comisión ostenta tal competencia porque la sentencia condena el abono de tales cantidades en la cuenta "Recursos propios de la Unión Europea". En tanto en cuanto es la Comisión quien ejecuta el presupuesto en virtud del artículo 317 TFUE y de conformidad con los Reglamentos adoptados en virtud del artículo 322 TFUE $^{56}$, la Comisión es competente para recaudar tales montantes. Podemos ver, por tanto, que fue el TJUE y no los tratados quien otorgó la competencia recaudatoria a la Comisión cuando dispuso el destino de la multa coercitiva y la suma a tanto alzado (Recursos propios...) en sus sentencias.

En cuanto al segundo de los problemas, el alcance de la competencia de la Comisión a la hora de verificar el completo cumplimiento de las obligaciones del Estado miembro para el cobro periódico de multas coercitivas, es algo más complejo. La Comisión ejerce su competencia recaudatoria a través de Decisiones en las que declara el devengo y requiere al Estado miembro en cuestión el pago de la multa coercitiva. En consecuencia, cada vez que la Comisión declara un nuevo devengo de la

55 STG de 19 de octubre de 2011, República Francesa/Comisión, T-139/06. Esta sentencia trata de resolver si la Comisión Europea actuó adecuadamente al considerar que Francia persistía en el incumplimiento determinado por el TJUE en su sentencia de 12 de julio de 2005, C-304/02, en relación a la conservación de los recursos pesqueros. Por tanto, lo que hace Francia es impugnar, ante el Tribunal General, la Decisión mediante la cual la Comisión recauda la multa coercitiva impuesta previamente.

56 "Toda vez que una sentencia del Tribunal de Justicia, dictada con arreglo al art. 228.2 TCE (260.2 TFUE), condena a un Estado miembro a pagar a la Comisión, mediante ingreso en la cuenta "Recursos propios de la Comunidad Europea", una multa coercitiva, y que la Comisión ejecuta el presupuesto en virtud del artículo 274 TCE (317 TFUE), le incumbe a esta recaudar las cantidades adeudadas al presupuesto de la Unión en ejecución de la sentencia, de conformidad con lo dispuesto en los Reglamentos adoptados en ejecución del artículo 279 CE (322 TFUE)", (apartado 37 de la sentencia mencionada). 
multa coercitiva está declarando, implícitamente, que el Estado miembro sigue incumpliendo sus obligaciones, lo que podría considerarse una potestad reservada al TJUE por los Tratados. El TJUE admite, según hemos señalado, esta potestad de la Comisión, pero tales Decisiones pueden ser objeto de recurso de anulación ante el Tribunal General, en el curso del cual el Estado miembro tendrá la oportunidad de demostrar que la Comisión se ha excedido en el mandato conferido por el TJUE en la sentencia.

En ocasiones, estas Decisiones liquidatorias de la Comisión han sido anuladas por el TG, al considerar que la Comisión se había excedido del mandato conferido por el TJUE en la sentencia previa ${ }^{57}$. El TG ha determinado que la Comisión debe adaptarse a los fallos del TJUE a la hora de liquidar las multas coercitivas, ya que esa resolución es la que delimita el ámbito de actuación de la Comisión. Así lo ha corroborado posteriormente el TJUE: "cuando el Tribunal de Justicia condena al Estado miembro al pago de una multa coercitiva, la comprobación de la Comisión de las medidas adoptadas por dicho Estado para dar cumplimiento a tal sentencia y el cobro de las cantidades adeudadas con arreglo a las sanciones impuestas deben realizarse teniendo en cuenta la delimitación del incumplimiento, tal como ha sido realizada por el Tribunal de Justicia en sus sentencias dictadas con arreglo a los arts. 258 y 260 TFUE" "58, y así lo había entendido también el Abogado General Nilo JäÄSKINEN, que defendió con buen criterio el hecho de que la competencia para determinar si el ordenamiento de un Estado miembro se adapta al Derecho de la Unión es una competencia exclusiva del TJUE, que no puede invadir la Comisión en el seno de una práctica meramente ejecutoria ${ }^{59}$.

En conclusión, si existe una discrepancia entre la Comisión y un Estado sobre si una normativa que no ha sido examinada por el TJUE es adecuada para ejecutar una sentencia, la Comisión no puede, mediante Decisión, resolver por sí misma tal discrepancia y extraer las consecuencias necesarias para el cálculo de la multa coercitiva.

${ }^{57}$ STG de 29 de marzo de 2011, Portugal/Comisión, T-33/09.

58 STJUE de 15 de enero de 2014, Comisión/Portugal, G-292/11P, apartado 41.

${ }^{59}$ Conclusiones del Abogado General Nilo JäÄSkinen presentadas el 16 de mayo de 2013, asunto C-292/11 P, apartados 28 y 29: "el principio fundamental que debe guiar a la Comisión en el ejercicio de su competencia de control una vez que se ha dictado una sentencia en virtud del art. 260 TFUE es el de ejecución, es decir, la aplicación efectiva de lo dispuesto en el fallo de la sentencia dictada en virtud del art. 258 TFUE, y de la sentencia dictada conforme al art. 260 TFUE. Este planteamiento es el único que garantiza la seguridad jurídica y la autoridad de las sentencias del TJUE y la exigencia de seguridad jurídica es aún más importante cuando se trata de obligaciones pecuniarias impuestas a los Estados miembros". 
Conviene no olvidar en este debate que quien fija inicialmente el objeto del proceso es la propia Comisión en la fase precontenciosa, al fijar el incumplimiento en sus conversaciones con el Estado. Por lo tanto, el hecho de que el petitum de la Comisión en la fase de liquidación de la multa coercitiva sea diferente al fallo del TJUE (que viene, a su vez, fijado por la fase precontenciosa) no es admitido por el TJUE ni por el TG, ya que en otro caso podría suponer la vulneración por parte de la Comisión del principio de venire contra factum proprium non valet, así como una vulneración del derecho de defensa de los Estados miembros.

Una vez resuelto este caso con la delimitación de las competencias de la Comisión, surge la duda de qué camino debería tomar la Comisión en caso de que considere, en fase de liquidación de multa coercitiva, que el Estado no ha dado cumplimiento a la sentencia dictada en virtud de los arts. 258 y 260 TFUE. El Abogado General Nilo JÄÄSKINEN trata de dar cierta luz a esta problemática cuestión indicando que "la Comisión está obligada a interponer un nuevo recurso por incumplimiento sobre la base del art. 258 TFUE cuando el litigio que la enfrenta con un Estado miembro excede del marco delimitado por el fallo del TJUE al amparo del art. 258 "60 ya que considera que es la única forma de proteger los derechos de defensa de los Estados miembros. No obstante, aclara que "compete a la Comisión asegurarse de que el Estado miembro de que se trata no se ha limitado a adoptar aquellas medidas que, en realidad, tienen el mismo contenido que aquella que fue objeto de sentencia del TJUE. Así pues, una modificación "cosmética" no puede sustraerse del control de la Comisión"61.

Por último, cabe preguntarse qué sucede si un Estado se niega finalmente a pagar las cantidades impuestas por el Tribunal y requeridas por la Comisión. Según L. Prete y B. Smulders, normalmente se considera que la Unión podría retener los pagos a ese Estado miembro de las sumas adeudadas por diferentes razones, procediendo a una especie de "compensación de deudas"62.

\section{BREVES GONCLUSIONES}

El progreso de la UE como organización se ha basado en muchas ocasiones en el método ensayo-error, de lo que podemos encontrar un buen ejemplo en el re-

${ }^{60}$ Conclusiones del Abogado General Nilo JäÄskinen presentadas el 16 de mayo de 2013, asunto C-292/11 P, apartado 77.

${ }^{61}$ Conclusiones del Abogado General NiloJäÄSKINEN presentadas el 16 de mayo de 2013, asunto C-292/11 P, apartado 35.

${ }^{62}$ L. Prete y B. Smulders, "The coming of age of infringement proceedings", cit. p. 55. 
curso por incumplimiento regulado en los arts. 258 - 260 TFUE. Cuando se observó que con una mera declaración de incumplimiento no bastaba para conseguir la aplicación del Derecho de la Unión, surgió el procedimiento de inejecución de sentencia, cuyo objeto es, en palabras del TJUE, "inducir al Estado miembro infractor a ejecutar una sentencia dictada en un procedimiento de incumplimiento". En el seno de este recurso, la multa coercitiva y la suma a tanto alzado se postulan como herramientas esenciales para que, finalmente, el Estado demandado cumpla con el compromiso originario de su adhesión a esta organización: aplicar el Derecho de la Unión.

En relación con esta última cuestión, el hecho de que en un principio el propio Tribunal calificara este procedimiento como "un especial procedimiento de ejecución" invitaba a pensar que las medidas que se tomaran en virtud del mismo serían medidas de ejecución. Sin embargo, la evolución jurisprudencial analizada en este trabajo ha demostrado que, si bien la multa coercitiva se puede asimilar a una medida de ejecución, la suma a tanto alzado se aproxima más a una sanción. Sirva como argumento el hecho de que, una vez ha desaparecido el incumplimiento del Estado miembro, desaparece la multa coercitiva pero se mantiene la suma a tanto alzado, tratando de castigar un pasado incumplidor. Esta afirmación, sin embargo, tiene importantes consecuencias, pues en el caso de que se asumiera su naturaleza sancionadora habría que volver a revisar algunas consideraciones de los Abogados Generales respecto a la aplicabilidad de algunos principios del Derecho sancionador, como el non bis in idem, el principio de legalidad o el de culpabilidad.

Como bien señaló la Comunicación de la Comisión Una Europa de resultados, "las instituciones europeas y los Estados miembros comparten un interés en mantener unas bases de la organización fuertes y necesitan hacer un compromiso aún más fuerte para asignar alta prioridad a la aplicación correcta de la ley. Los procedimientos de infracción están ahí para ayudar hacer eso". Como en muchos otros aspectos de la vida, la subsanación de los errores comienza por el diálogo, pero en ocasiones es necesario utilizar la coerción para llegar al resultado más legítimo.

\section{BIBLIOGRAFÍA}

Andrés SÁenz de SAnta María, P. "Primera multa coercitiva a un Estado miembro por inejecución de sentencia (Comentario a la STJCE de 4 de julio de 2000, Comisión/Grecia)", Revista de Derecho Comunitario Europeo, nº, (2000), pp. 493518.

Alonso García, Ricardo. "El soft law comunitario", Revista de Administración Pública $\mathrm{n}^{\circ}$ 154, 2001, pp. 63-94.

Alonso García, R. Sistema Jurídico de la Unión Europea, Civitas, Madrid, 2007. 
Bacigalupo Saggese, Mariano. "El sistema jurisdiccional de la Unión Europea" en Principios de Derecho de la Unión Europea, coord. Enrique Linde Paniagua, Colex, Madrid, 2011, pp. 544 y ss.

Barceló, M.J. Lecciones de derecho de la Unión Europea, Dir. Víctor M. SÁnchez, Bosch Internacional, Barcelona, 2008, pp. 245-256.

Díez-Hochleitner, J. "La respuesta del TUE al incumplimiento de Sentencias del Tribunal de Justicia por los Estados miembros", RIE, n 3, 1993, pp.837-900.

Díez Moreno, F. Manual de Derecho de la Unión Europea, Civitas, Navarra, 2009, p. 323 y ss.

Fajardo del Castillo, T. "Primera multa coercitiva a España en aplicación del procedimiento del artículo 228.2 del TCE: Comentario a la sentencia del TJCE de 25 de noviembre de 2003, asunto C-278/01, Comisión contra España", RGDE, n4, (2004), pp. 1-24.

Girón Larrucea, J.A. La Unión Europea. La Comunidad Europea y el Derecho Comunitario, Universidad de Sevilla, Sevilla, 2002, pp. 565 y ss.

Gómez de Liaño Fonseca, M. "La garantía jurisdiccional del Derecho Comunitario" en Instituciones de Derecho Comunitario, Colex, Madrid, 2009.

JACK, Brian. "Article 260.2 TFEU: An Effective Judicial Procedure for the Enforcement of Judgements?", European Law Fournal, Vol. 19, n 3, 2013, pp. 404-421.

Muñoz Pérez, M., Rubio González, A., y Abogados del Estado, "Capítulo IX: El recurso de incumplimiento", Procedimientos Administrativos y Fudiciales de la Unión Europea, Economist \& Jurist Difusión Jurídica, Madrid, 2012, pp. 455-587.

Pizarro Nevado, Rafael. "La multa coercitiva", Revista del Poder Fudicial, C.G.P.J, n 62, 2001, pp. 375-418.

Prete, L., and Smulders, B. "The coming of age of infringement proceedings", Common Market Law Review, n 47, 2010, pp. 9-61.

Rebollo Puig, Manuel y Bueno Armijo, Antonio. "Administrative procedures prior to the action for failure to fulfil an obligation", Parlamento Europeo, Bruselas, 2011 (PE432-765), disponible en http://www.europarl.europa.eu/studies. Edición española publicada en Mercedes FuERTEs LÓPEZ (coord.), Un procedimiento administrativo para Europa, Aranzadi, 2012, pp. 339-368.

Ruiz Jarabo-Colomer, D. La justicia de la Unión Europea, Civitas, Navarra, 2011, pp. 130 y ss.

SÁnchez Legido, Ángel. "El sistema judicial comunitario", en Instituciones de Derecho Comunitario, coord. Rosario Huesa VinaIXA, Tirant lo Blanch, Valencia, 2000, pp. 243- 316.

SÁnchez Rivera, Pedro. "Las multas coercitivas del Tribunal de Justicia de las Comunidades Europeas", Noticias de la Unión Europea núm. 294, (2009), pp. 145-154.

Silva de Lapuerta, Rosario. "La ejecución de las sentencias de incumplimiento por los Estados miembros", Noticias jurídicas de la Unión Europea, n 178, 1999, pp. 77-86. 
Sobrido Prieto, Marta. "Primera condena al pago simultáneo de una multa coercitiva y de una suma a tanto alzado por inejecución de sentencia. Comentario a la STJCE de 12 de julio de 2005, C-304/02, Comisión/Francia", RGDE, n 9 9, (2006), pp. 1-35.

TAMmES, A.J.P. "Soft Law", International and Comparative Law in Honour of Judge Erades, Martinus Nihoff Publishers, 1983, p. 64.

\section{VI. ÍNDICE JURISPRUDENGIAL}

STJCE de 4 de julio de 2000, Comisión/Grecia, as. C-387/97.

STJUE de 25 de noviembre de 2003, Comisión/España, as. C-278/01.

STJUE de 15 de julio de 2004, Comisión/Francia, as. C-419/03.

STJUE de 2 de diciembre de 2004, Comisión/Grecia, as. C-378/13.

STJUE de 12 de julio de 2005, Comisión/Francia, as. C-304/02.

STJUE de 18 de julio de 2006, Comisión/Italia, as. C-119/04.

STJUE de 18 de julio de 2007, Comisión/Alemania, as. C-503/04.

STJUE de 9 de diciembre de 2008, Comisión/Francia, as. C-121/07.

STJUE de 19 de mayo de 2009, Comisión/Italia, as. C-531/06.

STJUE de 10 de septiembre de 2009, Comisión/Portugal, as. C-457/07.

STJUE de 31 de marzo de 2011, Comisión/Grecia, as. C-407/09.

STJUE de 17 de noviembre de 2011, Comisión/Italia, as. C-496/09.

STJUE de 11 de diciembre de 2012, Comisión/España, as. C-610/10.

STJUE de 16 de diciembre de 2012, Comisión/Irlanda, as. C-374/11.

STJUE de 30 de mayo de 2013, Comisión/Suecia, as. C-270/11.

STUJE de 25 de junio de 2013, Comisión/República Checa, as. C-241/11.

STJUE de 17 de octubre de 2013, Comisión/Bélgica, as. C-533/11.

STJUE de 28 de noviembre de 2013, Comisión/Luxemburgo, as. C-576/11.

STJUE de 15 de enero de 2014, Comisión/Portugal, as. G-292/11P.

STJUE de 13 de mayo de 2014, Comisión/España, as. C-184/11.

STJUE de 2 de diciembre de 2014, Comisión/Italia, as. C-196/13.

STJUE de 4 diciembre de 2014, Comisión/Suecia, as. C-243/13.

STJUE de 16 de julio de 2015, Comisión/Italia, as. C-653/13.

STG de 29 de marzo de 2011, Portugal/Comisión, as. T-33/09.

STG de 19 de octubre de 2011, República Francesa/Comisión, as. T-139/06

STC de 14 de diciembre de 1988, núm. 239/1988. Ponente: Don Fernando García- Mon y González Regueral.

Conclusiones de los Abogados Generales del TJUE:

Conclusiones del Abogado General Mischo presentadas el 12 de junio de 2003, asunto C-278/01, Comisión/España.

Conclusiones del Abogado General Kокотт presentadas el 28 de enero de 2010, asunto C-526/08, Comisión/Luxemburgo. 
Conclusiones del Abogado General MazaK presentadas el 6 de septiembre de 2012 en el asunto C-610/10, Comisión/España.

Conclusiones del Abogado General JÄÄSKInEN presentadas el 16 de mayo de 2013, asunto C-292/11 P, Comisión/Portugal. 